\title{
Robust DTC Control of Doubly-Fed Induction Machines Based on Input-Output Feedback Linearization Using Recurrent Neural Networks
}

\author{
Amir Farrokh Payam*, Mohammad Naser Hashemnia ${ }^{\dagger}$, and Jawad Faiz* \\ ${ }^{*}$ Center of Excellence on Applied Electromagnetic Systems, University of Tehran, Tehran, Iran \\ ${ }^{\dagger}$ Department of Electrical Engineering, Sharif University of Technology, Tehran, Iran
}

\begin{abstract}
This paper describes a novel Direct Torque Control (DTC) method for adjustable speed Doubly-Fed Induction Machine (DFIM) drives which is supplied by a two-level Space Vector Modulation (SVM) voltage source inverter (DTC-SVM) in the rotor circuit. The inverter reference voltage vector is obtained by using input-output feedback linearization control and a DFIM model in the stator $\mathrm{a}-\mathrm{b}$ axes reference frame with stator currents and rotor fluxes as state variables. Moreover, to make this nonlinear controller stable and robust to most varying electrical parameter uncertainties, a two layer recurrent Artificial Neural Network (ANN) is used to estimate a certain function which shows the machine lumped uncertainty. The overall system stability is proved by the Lyapunov theorem. It is shown that the torque and flux tracking errors as well as the updated weights of the ANN are uniformly ultimately bounded. Finally, effectiveness of the proposed control approach is shown by computer simulation results.
\end{abstract}

Key Words: Artificial Neural Network, Direct Torque Control, Doubly Fed Induction Machine, Feedback linearization

\section{INTRODUCTION}

Doubly-fed induction generator (DFIG) wind turbines with converters rated at about $25-30 \%$ of the generator rating are becoming increasingly popular. DFIG-based wind turbines offer variable speed constant frequency (VSCF) operation, fourquadrant and decoupled active and reactive power capabilities, lower converter cost and reduced power loss when compared to other wind turbines. In a DFIG system, the stator is usually connected to a phase grid directly and the rotor is fed by two back-to-back pulse width modulation (PWM) or space vector modulation (SVM) inverters (Fig.1). This arrangement provides flexibility of operation at sub-synchronous and supersynchronous speeds in both generating and motoring modes. The power inverter only needs to be rated for a fraction of the total output power; the fraction depends on the permissible sub- and super-synchronous speed range [1].

So far both vector control (VC) and direct torque control (DTC) methods have been widely applied to squirrel cage induction machine drives [2]. Although field oriented vector methods have been applied to DFIM drives [3], [4], little attention has been paid to DTC and flux control of these types of drives. In field the oriented methods applied to DFIM

\footnotetext{
Manuscript received Jul. 28, 2010; revised Jul. 18, 2011

Recommended for publication by Associate Editor Kyeong-Hwa Kim.

$\dagger$ Corresponding Author: naserhashemnia@ee.sharif.edu

Tel: +98-021-66165961, Sharif University of Technology

* Department of Electrical Engineering, Sharif University of Technology, Iran
}

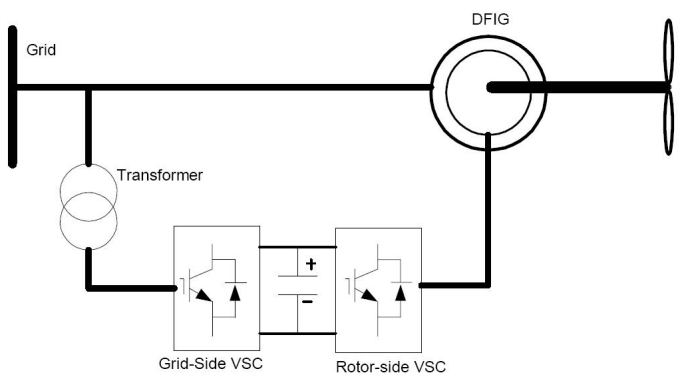

Fig. 1. A grid connected doubly-fed induction generator and its inverters.

drives, in order to design the rotor current controllers, it is necessary to neglect the voltage drop across the stator leakage impedance [3]-[5]. Therefore, the injected active and reactive powers to the stator can be independently controlled. This assumption leads to a steady-state error in both the motoring and generating modes of operation. In [6] the conventional bang-bang DTC method is combined with the direct rotor flux field oriented control method and applied to an adjustable speed DFIM drive. The DTC controller is designed based on neglecting the voltage drop across the rotor resistance. In [7] and [8], a back stepping tracking controller has been introduced for a DFIM drive. However, only unity power factor operation, measured on the stator supply voltage side, has been proposed. In [9], a stator power factor adjustable DTC method was proposed to control wound rotor doublefed induction machines. The implementation of the rotor flux based method and the stator power factor adjustable method 
requires information from both the stator side and the rotor side. Consequently the complexity of the control system is increased.

In [10], a DTC strategy was proposed for the DFIG used in variable speed wind power generation systems. Instead of the rotor flux or the stator power factor, the power factor of the rotor is controlled and kept at unity. This results in a control system, simplicity and a reduction of the inverter power rating. In order to reduce the torque and the stator current ripple, an ANN based hysteresis torque and flux controller was proposed in [11] for DFIMs. Simulation results show the superiority of this method over conventional bang-bang DTC control methods. However, there is no proof of the stability of the overall system. Moreover, the robustness of the system to machine parameter variations was not investigated.

Instead of using one converter in the rotor circuit, two converters are used in each side of a DFIM, i.e. the rotor and the stator [12]. One converter controls the stator flux while the other controls the rotor flux separately. This method, known as the Dual-DTC strategy, uses two switching tables for the stator and rotor converters. Although interesting features and more degree of freedom arise by using the Dual-DTC approach, higher complexity and an increase in the cost of the system are inevitable.

The nonlinear control techniques reported so far for DFIM drives are mostly parameter dependent and seriously affected by machine parameter deviations.

Our contribution in this paper is to introduce a DTCSVM control scheme for DFIMs based on the input-output linearization technique, using a motor fifth order model in the stationary two axis reference frame with the stator currents and rotor fluxes as state variables. It is well known that input-output feedback control method needs to know the exact model of a system with known parameters [13]. As a result, such a controller can not guarantee system robustness against parameter uncertainties. In the last decade, some researchers have tried to solve this problem by using the adaptive inputoutput feedback control method or the adaptive back stepping control approach [14], [15]. These two methods can make a drive system robust and stable to unknown constant parameters. To overcome this problem, this paper uses a two layer recurrent ANN to estimate the lumped uncertainty function of the system. Having estimated this function, it will be shown that the drive system is robust to most electrical parameter variations.

ANN weights are on-line tuned based on an estimation law which is obtained by the Lyapunov stability theorem. As a result, in this method, there is no need to know the actual value of the function which is supposed to be estimated. In addition, by this method the boundedness of the tracking errors and the updated ANN weights can be guaranteed.

\section{Doubly-Fed Induction Machine Model}

For a linear magnetic circuit and balanced operating conditions, the equivalent two-phase model of a symmetrical DFIM, represented in the fixed stator a-b reference frame with its stator directly connected to the grid is:

$$
\begin{aligned}
\frac{d i_{a s}}{d t} & =-\left(\frac{R_{s}}{L_{\sigma}}+\frac{R_{r} L_{m}^{2}}{L_{r}^{2} L_{\sigma}}\right) i_{a s}+\frac{R_{r} L_{m}}{L_{r}^{2} L_{\sigma}} \psi_{a r}+\frac{\omega_{r} L_{m}}{L_{r} L_{\sigma}} \psi_{b r} \\
& +\frac{u_{a s}}{L_{\sigma}}-\frac{L_{m}}{L_{r} L_{\sigma}} u_{a r} \\
\frac{d i_{b s}}{d t} & =-\left(\frac{R_{s}}{L_{\sigma}}+\frac{R_{r} L_{m}^{2}}{L_{r}^{2} L_{\sigma}}\right) i_{b s}+\frac{R_{r} L_{m}}{L_{r}^{2} L_{\sigma}} \psi_{b r}-\frac{\omega_{r} L_{m}}{L_{r} L_{\sigma}} \psi_{a r} \\
& +\frac{u_{b s}}{L_{\sigma}}-\frac{L_{m}}{L_{r} L_{\sigma}} u_{b r} \\
\frac{d \psi_{a r}}{d t} & =\frac{R_{r} L_{m}}{L_{r}} i_{a s}-\frac{R_{r}}{L_{r}} \psi_{a r}-\omega_{r} \psi_{b r}+u_{a r} \\
\frac{d \psi_{b r}}{d t} & =\frac{R_{r} L_{m}}{L_{r}} i_{b s}-\frac{R_{r}}{L_{r}} \psi_{b r}+\omega_{r} \psi_{a r}+u_{b r}
\end{aligned}
$$

where $i_{s}, \psi_{r}, u_{s}, u_{r}, R$ and $L$ denote the stator currents, the rotor flux linkage, the stator terminal voltage, the rotor terminal voltage, the resistance and the inductance, respectively. The subscripts $\mathrm{s}$ and $\mathrm{r}$ stand for the stator and rotor, while the subscripts $a$ and $b$ stand for the vector component with respect to a fixed stator reference frame. $\omega_{r}$ denotes the rotor electrical speed and $L_{m}$ is the mutual inductance. $L_{\sigma}=L_{s}\left(1-\left(\frac{L_{m}^{2}}{L_{r} L_{s}}\right)\right)$ is the redefined leakage inductance.

The generated torque of a DFIM in terms of the stator current and the rotor flux linkage components is as follows:

$$
T_{e}=\mu\left(\psi_{a r} i_{b s}-\psi_{b r} i_{a s}\right)
$$

where $\mu=\frac{3 P}{2} \frac{L_{m}}{L_{r}}$ and $P$ is the number of poles. The mechanical dynamic equation is given by:

$$
J \frac{d \omega_{m}}{d t}+B \omega_{m}+T_{L}=T_{e}
$$

where $J$ and $B$ denote the moment of inertia of the motor and the viscous friction coefficient, respectively. $T_{L}$ is the external load torque and $\omega_{m}$ is the rotor mechanical speed $\left(\omega_{r}=\left(\frac{P}{2}\right) \omega_{m}\right)$.

$$
x=\left[\begin{array}{llll}
i_{a s} & i_{b s} & \psi_{a r} & \psi_{b r}
\end{array}\right]^{T}
$$

Let be the state vector and let the generated torque $T_{e}$ be the output $y$ of the dynamic system (1), that is:

$$
y=T_{e}=\frac{3 P}{2} \frac{L_{m}}{L_{r}}\left(\psi_{a r} i_{b s}-\psi_{b r} i_{a s}\right) .
$$

It is well-known that torque control is very important for high-performance motion control [16]. However, from (1) and (5) the generated torque $T_{e}$ of a DFIM can be viewed as a nonlinear function of the state variables $x$ of the dynamic model (1), $i_{a s}, i_{b s}, \psi_{a r}$ and $\psi_{b r}$. Therefore, it is difficult to evaluate the torque response from (5) by the control inputs $u_{a r}$ and $u_{b r}$ designed for the model (1). Therefore, based on (1), it is a task for the torque control of induction machines in industrial and practical applications.

\section{InPut-OUtPut FeEdBACK CONTROL}

For the proposed nonlinear controller, the state coordinate transformation is applied. Therefore, the state-coordinates transformed model from (1) can be rewritten in the following compact form:

$$
\dot{x}=f(x)+g_{1} u_{a r}+g_{2} u_{b r}
$$


where $x$ is defined in (4) and:

$$
f(x)=\left[\begin{array}{c}
-\left(\frac{R_{s}}{L_{\sigma}}+\frac{R_{r} L_{m}^{2}}{L_{r}^{2} L_{\sigma}}\right) i_{a s}+\frac{R_{r} L_{m}}{L_{r}^{2} L_{\sigma}} \psi_{a r}+\frac{\omega_{r} L_{m}}{L_{r} L_{\sigma}} \psi_{b r}+\frac{u_{a s}}{L_{\sigma}} \\
-\left(\frac{R_{s}}{L_{\sigma}}+\frac{R_{r} L_{m}^{2}}{L_{r}^{2} L_{\sigma}}\right) i_{b s}+\frac{R_{r} L_{m}}{L_{r}^{2} L_{\sigma}} \psi_{b r}-\frac{\omega_{r} L_{m}}{L_{r} L_{\sigma}} \psi_{a r}+\frac{u_{b s}}{L_{\sigma}} \\
\frac{R_{r} L_{m}}{L_{r}} i_{a s}-\frac{R_{r}}{L_{r}} \psi_{a r}-\omega_{r} \psi_{b r} \\
\frac{R_{r} L_{m}}{L_{r}} i_{b s}-\frac{R_{r}}{L_{r}} \psi_{b r}+\omega_{r} \psi_{a r} \\
g_{1}=\left[\begin{array}{llll}
-\frac{L_{m}}{L_{r} L_{\sigma}} & 0 & 1 & 0
\end{array}\right]^{T} \\
g_{2}=\left[\begin{array}{llll}
0 & -\frac{L_{m}}{L_{r} L_{\sigma}} & 0 & 1
\end{array}\right]^{T} .
\end{array}\right.
$$

At this stage, the developed torque $T_{e}$ and the squared modules of the rotor flux linkage, $\left|\psi_{r}\right|^{2}=\psi_{d r}^{2}+\psi_{q r}^{2}$, are required to be the controlled outputs. Therefore, by considering:

$$
\begin{aligned}
& h_{1}(x)=\frac{3 P}{2} \frac{L_{m}}{L_{r}}\left(\psi_{a r} i_{b s}-\psi_{b r} i_{a s}\right) \\
& h_{2}(x)=\psi_{a r}^{2}+\psi_{b r}^{2}
\end{aligned}
$$

The controller output errors $e_{1}$ and $e_{2}$ are defined as follows:

$$
\begin{aligned}
& e_{1}=T_{e}-T_{e}^{\mathrm{r}} \\
& e_{2}=\left(\psi_{a r}^{2}+\psi_{b r}^{2}\right)-\psi_{r}^{r 2}=\psi_{r}^{2}-\psi_{r}^{r 2} .
\end{aligned}
$$

Then:

$$
\dot{e}=F+G v
$$

where:

$$
\begin{aligned}
& F=\left[\begin{array}{l}
F i_{1} \\
F i_{2}
\end{array}\right] \\
& F i_{1}=\frac{3 P}{2} \frac{L_{m}}{L_{r}} \times\left(\begin{array}{c}
-\left(\frac{R_{s}}{L_{\sigma}}+\frac{R_{r} L_{m}^{2}}{L_{r}^{2} L_{\sigma}}+\frac{R_{r}}{L_{r}}\right)\left(i_{b s} \psi_{a r}-i_{a s} \psi_{b r}\right)- \\
\frac{\omega_{r} L_{m}}{L_{r} L_{\sigma}}\left(\psi_{a r}^{2}+\psi_{b r}^{2}\right)-\omega_{r}\left(\psi_{b r} i_{b s}+\psi_{a r} i_{a s}\right) \\
\left.+\frac{u_{b s} \psi_{a r}}{L_{\sigma}}-\frac{u_{a s} \psi_{b r}}{L_{\sigma}}\right)
\end{array}\right) \\
& F i_{2}=2 \frac{R_{r} L_{m}}{L_{r}}\left(i_{a s} \psi_{b r}-i_{b s} \psi_{a r}\right)-2 \frac{R_{r}}{L_{r}}\left(\psi_{a r}^{2}+\psi_{b r}^{2}\right) \\
& G=\left[\begin{array}{cc}
\frac{3 P}{2} \frac{L_{m}}{L_{r}}\left(i_{b s}+\frac{L_{m}}{L_{r} L_{\sigma}} \psi_{b r}\right) & -\frac{3 P}{2} \frac{L_{m}}{L_{r}}\left(i_{a s}+\frac{L_{m}}{L_{r} L_{\sigma}} \psi_{a r}\right) \\
2 \psi_{b r}
\end{array}\right] \text { (14) } \\
& v=\left[\begin{array}{l}
v_{a r} \\
v_{b r}
\end{array}\right] \text {. }
\end{aligned}
$$

Based on the input-output feedback linearization method, the following control inputs are introduced for the system.

$$
v=G^{-1}[-F-K e], \quad K>0 .
$$

\section{ANN BASICS}

Recent developments in the field of Neuro-computing present ANN as a potential controller for slip-energy recovery drive systems. ANNs are valuable on several counts. For example, they are capable of performing massive parallel processing and can provide a good degree of fault tolerance. Furthermore, ANNs are adaptive, in that they can learn and

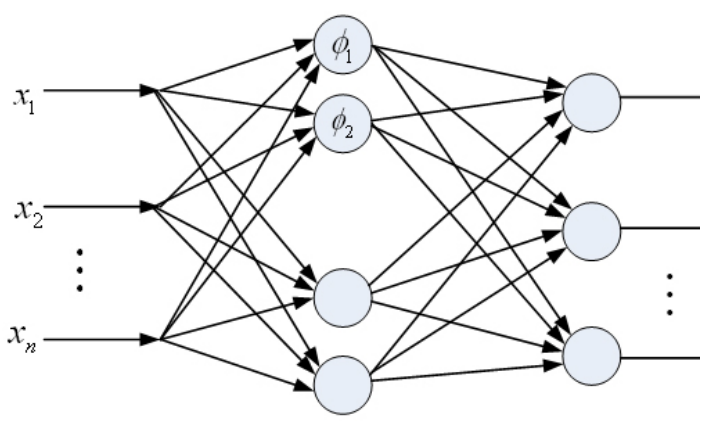

Fig. 2. Two Layer ANN.

infer solutions from the data presented to them by learning the underlying relationships even if these relationships are difficult to find and describe. ANNs can precisely process data which may be different from the data used in the training stage. Moreover, ANNs may be able to handle imperfect or noisy data. Finally, ANNs can approximate a wide range of nonlinear functions to any desired degree of accuracy under certain conditions [17]. In the application of a drive system, ANNs can be trained to emulate the nonlinear dynamics of that system by learning a suitable sets of input/output patterns for it [18].

The structure of a two-layer ANN has been shown in Fig. 2. $W$ is defined as a collection of $\mathrm{NN}$ weights and $\phi$ as basis functions. Then the net output is:

$$
y=W^{T} \phi(x)
$$

Let $S$ be a compact simply connected set of $\mathbb{R}^{n}$. With the $\operatorname{map} f: S \rightarrow \mathbb{R}_{n}$. Define $C^{m}(S)$ as the functional space such that $f$ is continuous [19]. A general nonlinear function $f(x) \in$ $C^{m}(S), x(t) \in S$, can be approximated by an ANN as:

$$
f(x)=W^{T} \phi(x)+\varepsilon(x)
$$

where $\varepsilon(x)$ is the bounded NN functional reconstruction error vector and $\phi$ is the sigmoid activation function [20].

\section{ANN CONTRoller Design}

In order to make the drive control system robust against machine parameter uncertainties, the ANN controller is designed as:

$$
v=G^{-1}[-\hat{F}-K e], K>0
$$

where $\hat{F}$ is the online estimate of the nonlinear function $F$, which is the output of the two layer ANN (with the general structure shown in Fig. 2) through (17) as:

$$
F=W^{T} \phi+\varepsilon
$$

And:

$$
\hat{F}=\hat{W}^{T} \phi
$$

Note that in (19) $W$, as a collection of NN weights, is constant and bounded by a known positive value. Also, the reconstruction error is bounded by a known value.

Equations (11), (18), (19) and (20) lead to:

$$
\dot{e}=\tilde{W}^{T} \phi-K e+\varepsilon .
$$


It is noted that the actual inputs to the chosen ANN are the rotor fluxes, the stator currents, the rotor speed and the torque reference. Using the Lyapunov theory and considering (18) and (21), the ANN weights may be estimated on-line by the following equation:

$$
\dot{\hat{W}}^{T}=\Gamma \phi e^{T}-k_{\omega} \Gamma\|e\| \hat{W} .
$$

By estimating the function $\hat{F}$ and using the Lyapanouv analysis, it can be seen that the torque and stator flux error signals as well as the ANN updated weights are all UUB [20].

\section{Stator Active and Reactive Power Control}

For the generating mode of operation of DFIMs, it is required to regulate the stator active-reactive power, whose references are $P_{s}^{*}$ and $Q_{s}^{*}$, respectively. In [21], a synchronous $\mathrm{d}$ and $\mathrm{q}$ axis rotating reference frame with $\mathrm{d}$ axes coinciding with the space voltage vector for the main ac supply has been considered. Stator active-reactive power control has been expressed in terms of the stator current as:

$$
\begin{aligned}
i_{q}^{*} & =\frac{3}{2} \frac{Q_{s}^{*}}{U} \\
i_{d}^{*} & =\frac{3}{2} \frac{P_{s}^{*}}{U} .
\end{aligned}
$$

It is assumed that a prime mover maintains the rotor speed at constant value during the generating mode. For the motoring mode of operation, the torque and stator reactive power control objectives have been converted to stator current control [21]. In addition, the rotor flux references can be obtained as:

$$
\begin{aligned}
& \psi_{d}^{*}=\frac{1}{\beta \omega_{0}}\left(-\frac{R_{s}}{\sigma} i_{q}^{*}-\omega_{0} i_{d}^{*}\right) \\
& \psi_{q}^{*}=\frac{1}{\beta \omega_{0}}\left(\frac{R_{s}}{\sigma} i_{d}^{*}-\omega_{0} i_{q}^{*}-\frac{1}{\sigma} U\right) .
\end{aligned}
$$

Therefore, the rotor flux reference and the torque reference are calculated as:

$$
\begin{aligned}
& \psi_{r}^{*}=\sqrt{\left(\psi_{d}^{* 2}+\psi_{q}^{* 2}\right)} \\
& T_{e}^{*}=\mu\left(\psi_{d}^{*} i_{q}^{*}-\psi_{q}^{*} i_{d}^{*}\right) .
\end{aligned}
$$

\section{Stabilization of Rotor DC Link Voltage}

It is necessary to maintain the rotor dc-link voltage constant during drive system operation. This can be achieved using a supply side three-phase PWM converter as shown in Fig. 3. With proper control of this converter, the rotor dc link voltage can be maintained constant regardless of the magnitude and the direction of the rotor power. The vector control of this inverter, with a reference frame oriented along the stator (or supply) voltage vector position, enables independent control of the active and reactive powers flowing between the supply and the supply-side converter [22], [23]. At this end, a capacitor in the dc-link and supply-side converter is used to mitigate variations of the capacitor voltage due to variations of the rotor power.

Using the control method described in [22], the $\mathrm{d}$ and $\mathrm{q}$ axis equations corresponding to the main ac power supply in

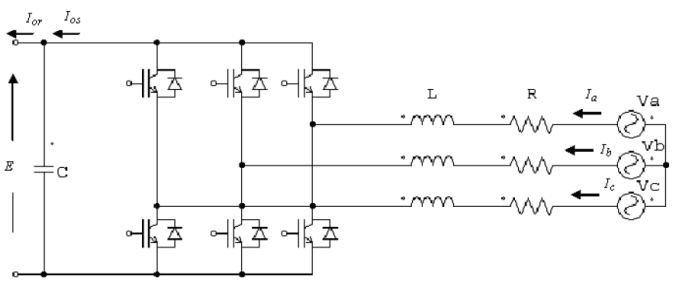

Fig. 3. Connection of inverter to main supply.

a particular synchronous rotating reference frame with a $\mathrm{d}$ axis coinciding with the voltage space vector are given by:

$$
\begin{aligned}
& \frac{d i_{d}}{d t}=\frac{1}{L}\left(v_{d}-R i_{d}+\omega_{e} L i_{q}-v_{d 1}\right) \\
& \frac{d i_{q}}{d t}=\frac{1}{L}\left(-R i_{q}-\omega_{e} L i_{d}-v_{q 1}\right) .
\end{aligned}
$$

One may note that in this reference frame, the $d$ axis being coincident with the main space voltage vector means that:

$$
v_{d}=v_{s}, \text { and } v_{q}=0 .
$$

By considering $i_{d}^{*}$ and $i_{q}^{*}$ as reference currents, the current errors are:

$$
\begin{aligned}
& e_{1}^{\prime}=i_{d}-i_{d}^{*} \\
& e_{2}^{\prime}=i_{q}-i_{q}^{*} .
\end{aligned}
$$

Consequently, the system error dynamics are:

$$
\begin{aligned}
& \dot{e}_{1}{ }_{1}=\frac{v_{d}}{L}-\frac{R}{L} i_{d}+\omega_{e} i_{q}-\frac{v_{d 1}}{L}-i_{d}^{*} \\
& \dot{e}^{\prime}{ }_{2}=-\frac{R}{L} i_{q}-\omega_{e} i_{d}-\frac{v_{q 1}}{L}-i_{q}^{*} .
\end{aligned}
$$

Define the AC side inverter reference voltages as:

$$
\begin{aligned}
& v_{d 1}=L\left(\frac{v_{d}}{L}-\frac{R}{L} i_{d}+\omega_{e} i_{q}-i_{d}^{*}+k e_{1}^{\prime}\right) \\
& v_{q 1}=L\left(-\frac{R}{L} i_{q}-\omega_{e} i_{d}-i_{q}^{*}+k e_{2}^{\prime}\right) .
\end{aligned}
$$

Linking (27) and (28), gives:

$$
\begin{aligned}
\dot{e}_{1}^{\prime} & =-k e_{1}^{\prime} \\
\dot{e}_{2}^{\prime} & =-k e_{2}^{\prime} .
\end{aligned}
$$

Considering the Lyapunov function as:

$$
V=\frac{1}{2} e_{1}^{\prime 2}+\frac{1}{2} e_{2}^{\prime 2} .
$$

The derivative of this function becomes:

$$
\dot{V}=\dot{e}^{\prime}{ }_{1} e_{1}^{\prime}+\dot{e}^{\prime}{ }_{2} e_{2}^{\prime}=-k\left(e_{1}^{\prime 2}+e_{2}^{\prime 2}\right)<0 .
$$

Neglecting the losses in the supply side converter, the injected active power to the rotor is:

$$
P_{r}=E i_{o r} .
$$

Also, from Fig. 3, one can obtain:

$$
\begin{gathered}
\frac{3}{2} v_{d} i_{d}=E i_{o s} \\
C \frac{d E}{d t}=i_{o s}-i_{o r} .
\end{gathered}
$$




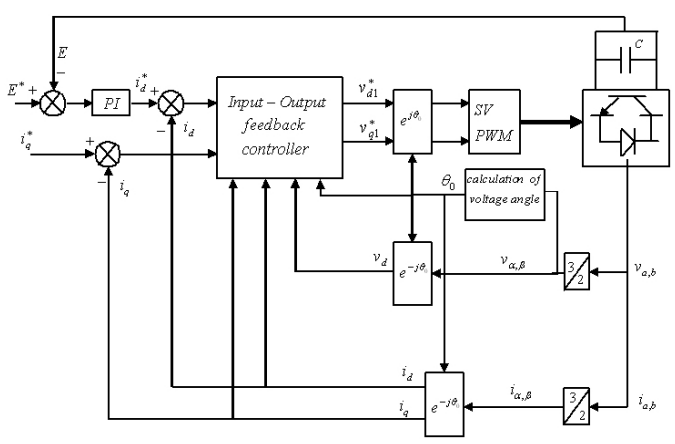

Fig. 4. DC-link voltage controller [23].

By substituting $i_{o r}$ and $i_{o s}$ from equations (33) and (34) into (34), the rotor dc link voltage variation is obtained as:

$$
d E=\frac{1}{C}\left(\frac{3}{2} \frac{v_{d} i_{d}}{E}-\frac{P_{r}}{E}\right) d t .
$$

Based on the proposed theory, the block diagram shown in Fig. 4 is proposed to keep the rotor dc link voltage constant.

\section{SYSTEM SIMULATION}

An overall block diagram of the proposed control approach is shown in Fig. 5. The proposed approach has been applied to a three-phase, $5 \mathrm{~kW}, 380 \mathrm{~V}$, 6-pole, $50 \mathrm{~Hz}$ DFIM drive and the simulation results are shown in Fig. 6-11. The simulation results shown in Fig. 6 are for the motoring mode of operation, as well as the sub and super synchronous speeds, with $R_{r}=$ $3 R_{r n}, R_{s}=3 R_{s n}$.

The motor load torque varies between $10 \mathrm{Nm}$ and $30 \mathrm{Nm}$ for each half second. $R_{r n}, R_{s n}$ are the nominal rotor and stator resistances, respectively. From these results, it can be seen that the proposed torque and flux control scheme can quickly track the reference commands and is robust against parameter uncertainties. In this case, based on the proposed torque and flux control, a PI controller is used as the speed controller.

Fig. 7 and Fig. 8 show the simulation results obtained for the sub and super synchronous speed generator operating conditions with $\omega_{r}=290 \mathrm{rad} / \mathrm{sec}$ and $\omega_{r}=375 \mathrm{rad} / \mathrm{sec}$, respectively. It is obvious from these results that the proposed controller has high performance. In Fig. 6 the rotor active power is positive due to increases in the stator and rotor resistances. It is concluded from these Figs that ANN can estimate the system uncertainties and make the system robust against rotor and stator resistance variations.

Fig. 9 shows the drive system performance in generating mode above the synchronous speed. These results are obtained for the nominal condition, and the active and reactive power references as well as the torque and flux references are also shown in Fig. 9. The DC link voltage is represented by $\mathrm{E}$.

From Fig. 9, it is clear that in addition to active and reactive power control objective, which leads to the torque and flux control strategy, the DC link voltage is successfully stabilized by the input-output feedback linearization method.

For the sake of comparison, the method is this paper is compared with the one in [24], where a direct active and reactive power control strategy for DFIGs has been used. This method was first used in three-phase PWM rectifiers

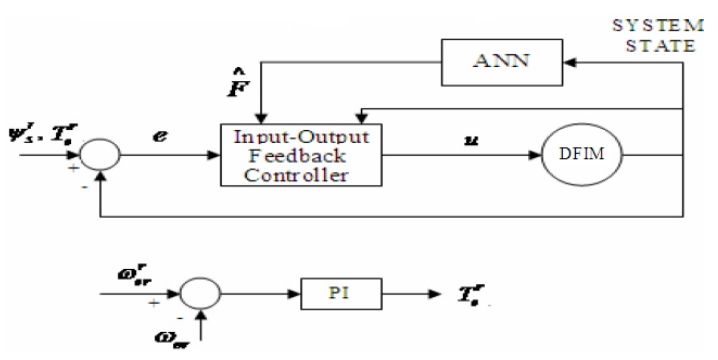

Fig. 5. Control block diagram of the system.
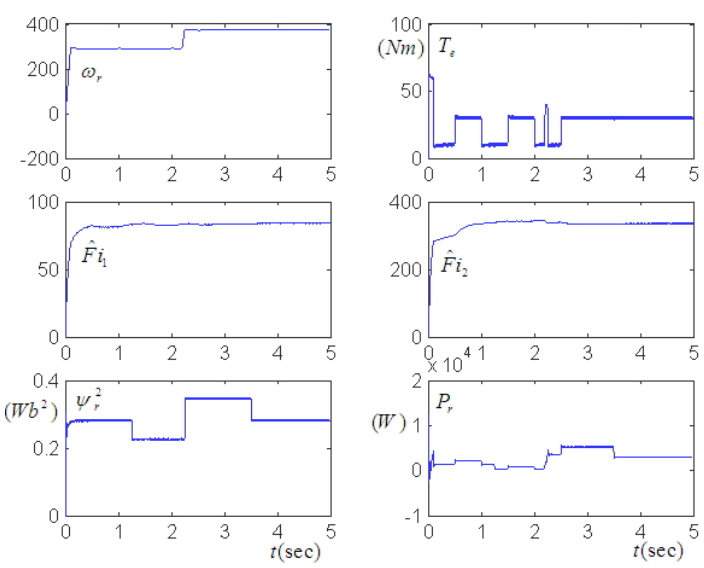

Fig. 6. Simulation results for motoring operation.
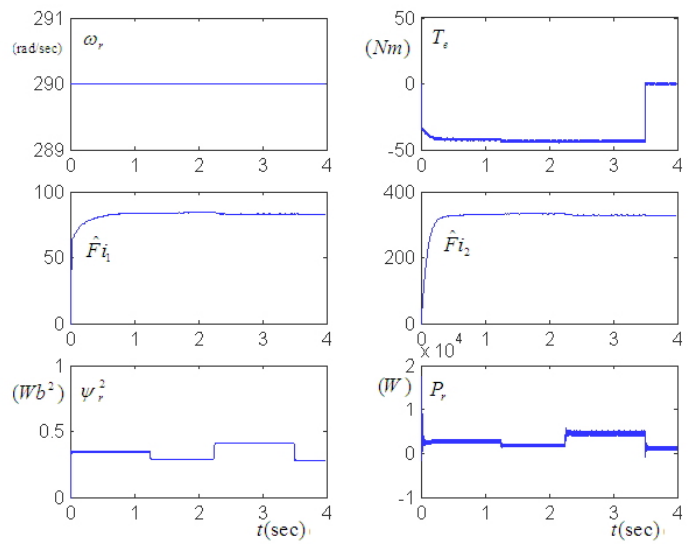

Fig. 7. Simulation results for generating sub-synchronous operation.
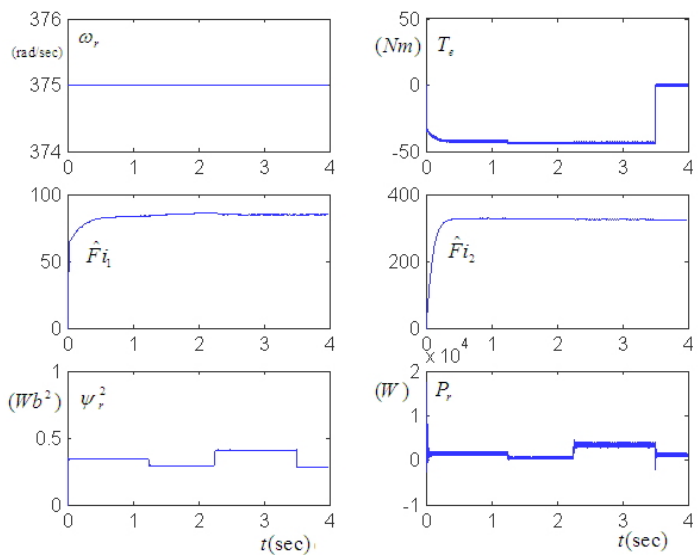

Fig. 8. Simulation results for generating super-synchronous operation. 

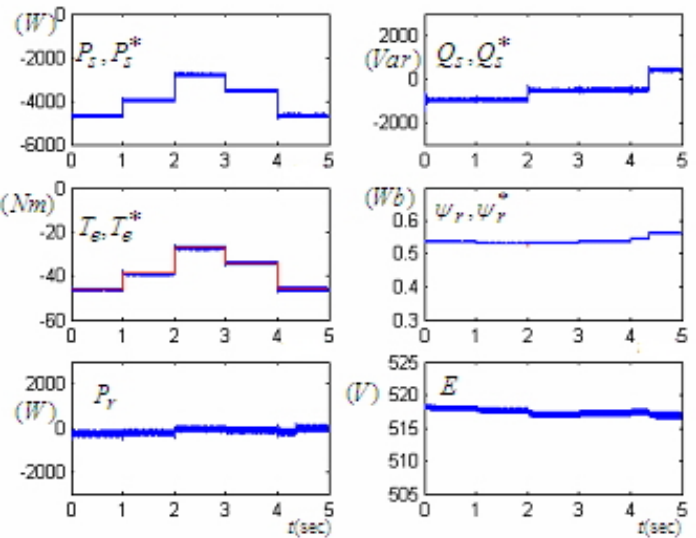

Fig. 9. Simulation results for generating mode above synchronous speed.
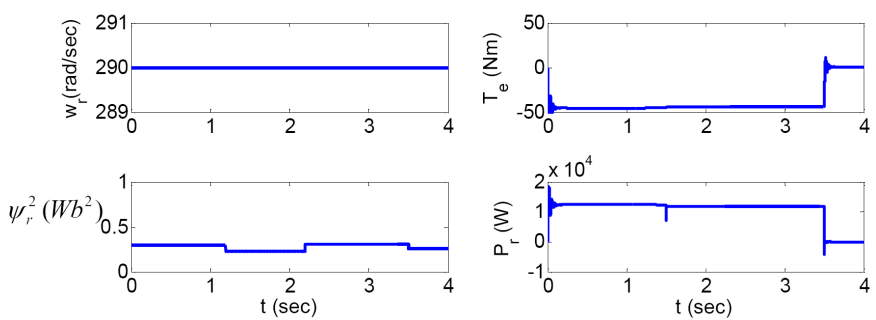

Fig. 10. Simulation results for generating mode below synchronous speed using the method in [24].

[25], where the converter switching states were selected from an optimal switching table based on the instantaneous errors between the reference and estimated values of the active and reactive powers, and the angular position of the estimated converter terminal voltage vector. In [24] two three-level hysteresis comparators were used to generate the respective active and reactive power states. Based on these states and also the position of the stator flux in the rotor reference frame, the optimal rotor voltage vector is selected. First the stator flux is estimated in the stationary reference frame using the following equation:

$$
\Psi_{s}^{s}=\int\left(V_{s}^{s}-R_{s} I_{s}^{s}\right) d t
$$

Since the amplitude and frequency of stator voltage are relatively fixed, an accurate estimation of the stator flux is provided using the above relation. It is then transformed to the rotor reference frame using the rotor angular position.

The presence of the rotor resistance is a critical problem in this method, since the impact of the rotor resistance on the rotor flux (as in the following relation) has been neglected:

$$
\frac{d \psi_{r}^{r}}{d t}=V_{r}^{r}-R_{r} I_{r}^{r}
$$

Therefore, the same problems in stator flux estimation at low speeds can arise in rotor flux estimation near synchronous speed and for high rotor resistance machines.

The method in [24] has been simulated and the results are depicted in figures 10 and 11 . It is obvious that the proposed controller is superior in terms of transient response and robustness to parameter variations.
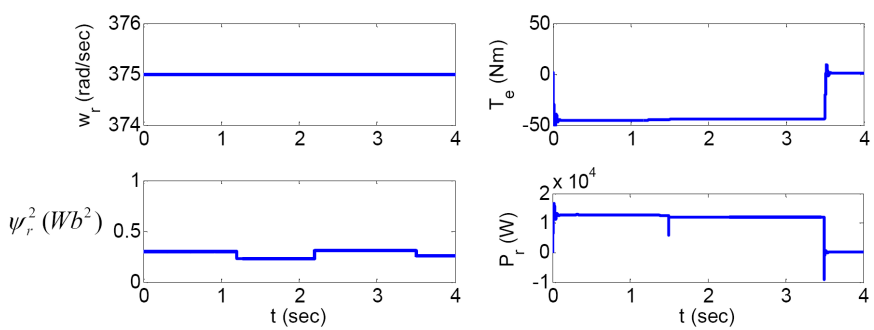

Fig. 11. Simulation results for generating mode above synchronous speed using the method in [24].

\section{CONCLUSIONS}

In this paper, a nonlinear controller was introduced based on the input-output feedback linearization control method for a doubly-fed induction machine, using a two layer ANN. The stability of this controller was proved by the Lyapunov theorem. It was shown that the tracking errors as well as the ANN updated weights are UUB. With this controller, perfect torque (or speed) and rotor flux tracking performances can be achieved despite rotor and stator resistances uncertainties and load torque disturbances. The proposed control approach was verified for both the motoring and generating modes of operation below and above the synchronous speed by simulation, using two level SV-PWM back-to-back voltage source inverters in the rotor circuit.

Furthermore, the rotor DC-link voltage was kept constant based on an input-output control method, using the rotating synchronous reference frame with a $\mathrm{d}$ axis coinciding with the direction of the space voltage vector of the main AC supply. Simulation results depict the effectiveness of the presented controller.

\section{REFERENCES}

[1] R. Datta and V. Ranganathan, "Variable-Speed Wind Power Generation Using a Doubly Fed Wound Rotor Induction Machine: A Comparison with Alternative Schemes," IEEE Power Engineering Review, Vol. 22, No. 7, pp. 52-55, Jul. 2002.

[2] D. Casrdei, F. Profumo, G. Serra and A.Tani, "FOC and DTC: two viable schemes for induction motors torque control," IEEE Trans. Power Electron., Vol.17, No. 5, pp. 779-787, Sep. 2002.

[3] B. Hopfensperger, J. Atkinson, and R.A.Lakin, "Stator-flux-oriented control of a doubly-fed induction machine with and without position encoder," IEE Proc. Electr. Power Appl, Vol. 147, No. 4, pp. 241-250, Jul. 2000.

[4] L. Xu, and W. Cheng, "Torque and reactive power control of a doublyfed wound rotor induction machine by position sensorless scheme," IEEE Trans, Ind. Appl, Vol. 31, No. 3, pp. 636-642, May/Jun. 1995.

[5] R.Pena, J. C.Clare, and G. M .Asher, "Doubly fed induction generator using back to back PWM convertor and its application to variable-speed wind energy generator," IEE Proc. Electr. Power. Appl, Vol. A3, No. 3, pp. 231-241, Nov. 1996.

[6] Z. Wang, F. Wang, M. Zong, and F. Zhang, "A new control strategy by combining direct torque control with vector control for doubly fed machines," in Proc.IEEE-Powercon'2004, Singapore, pp. 792-795, Nov. 2004.

[7] S .Peresada, A. Tilli, and A. Tonielli, "Robust active-reactive power control of a doubly-fed induction generator," in Proc.IEEE-IECON'98, Aachen, Germany, pp. 1621-1625, Sep. 1998.

[8] S. Peresada, A. Tilli, and A. Tonielli, "Indirect stator flux-oriented output feedback control of a doubly fed induction machine," IEEE Trans. Control Sys., Vol. 11, No. 6, pp. 875-888, Nov. 2003.

[9] O. A. Mohammed, Z. Liu, and S. Liu, "Stator power factor adjustable direct torque control of doubly-fed induction machines," in PROC. ICEMDC, pp. 572-578, May 2005. 
[10] Z. Liu, O. A. Mohammed, S. Liu, "A novel direct torque control of doubly-fed induction generator used for variable speed wind power generation", in PROC PES, pp. 1-6, Jun. 2007.

[11] R. Geetha, T. Thyagarajn, V. Subrshmanam, and R. Shilila, "Torque ripple minimization in Doubly Fed Induction Machine used in wind mills with Artificial Neural Network," Journal of Theoretical and Applied Information Technology, Vol. 7, No. 1, pp. 53-57, 2009.

[12] F. Bonnet, P. E. Vidal, and M. Pietrzak-David, "Direct torque control of doubly fed induction machine," Bulletin of the polish academy of sciences technical sciences, Vol. 54, No. 3, pp. 307-314, Oct. 2006.

[13] Marino R, Tomei P, Nonlinear Control Design-Geometric, Adaptive and Robust. Englewood Cliff: VJ: Prentice-Hall, 1995.

[14] I. Kanellakopoulos, P. V. Kokotovic and A. S. Morse, "Systematic Design of Adaptive Controllers for Feedback Linearizable Systems," IEEE Trans. Automat. Contr., Vol. 36, pp. 1241-1253, Nov. 1991.

[15] M. Krstic, I. Kannellakopoulos, and P. Kokotovic, Nonlinear and Adaptive Control Design, John Willey\&Sons, 1995.

[16] R. D. Lorenz, T. A. Lipo, and D. W. Novotny, "Motion Control with Induction Motors," in PROC IEEE, Vol. 82, pp. 1215-1240, Aug. 1994.

[17] O. Omidvar, D.L. Elliott, Neural Systems for Control. Academic Press, 1997.

[18] A.M.A Amin, "Neural network-based tracking control system for slipenergy recovery drives," in PROC IEEE, Vol. 3, pp. 1247-1252, Jul. 1997.

[19] N. Sadegh, "Nonlinear identification and control via neural networks in Control Systems with Inexact Dynamic Models," ASME Winter Annual. Meeting, Vol. 33, 1991.

[20] F. Kwan, L. Lewis, "Robust Backstepping Control of Nonlinear Systems Using Neural Networks," IEEE Trans. Systems Man and CyberneticsPart A: Systems and Humans, Vol. 30, No. 6, pp. 753-766, Nov. 2000.

[21] S. Peresada, A.Tilli and A.Tonielli, "Robust Output Feedback Control of a Doubly Fed Induction Machine," in PROC IEEE, Vol. 3, pp. 13481354, Nov./Dec. 1999.

[22] A .Farrokh Payam, "An Adaptive Input-Output Feedback Linearization Controller for Doubly-Fed Induction Machine Drives," Serbian Journal of Electrical Engineering, Vol. 5, No. 1, pp. 139-154, May 2008.

[23] B. Mirzaeian Dehkordi, A. Farrokh Payam, M. N. Hashemnia, and S. Sul, "Design of an adaptive back stepping controller for doubly-fed induction machine drives," Journal of Power Electronics, Vol. 9, No. 3, pp.343-353, May 2009.

[24] X. Lie, P. Cartwright, "Direct active and reactive power control of DFIG for wind energy generation", IEEE Trans Energy Convers., Vol. 21, No. 3, pp. 750-758, Sep. 2006.

[25] T. Noguchi, H. Tomiki, S. Kondo, and I. Takahashi, "Direct powe control of PWM converter without power-source voltage sensors," IEEE Trans on Ind. Appl., Vol. 34, No. 3, pp. 473-479, May/Jun. 1998.

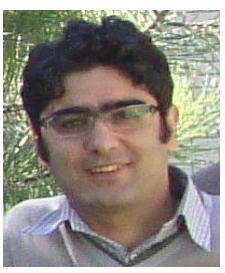

Amir Farrokh Payam received his B.S. in Electrical Engineering from the K.N.Toosi University of Technology, Tehran, Iran, in 2002 and his M.S. in Electrical Engineering from the Isfahan University of Technology, Isfahan, Iran, in 2006. Currently he is a Ph.D. studen of Nano-Electronics at the University of Tehran, Tehran, Iran. He was a visiting student at the Institute of Microelectronics of Madrid, Spain, from September 2010 to March 2011. His research interests include the dynamic, modeling and control of the Atomic Force Microscope, NEMS and MEMS, surface science, electrical drives and applied nonlinear control.

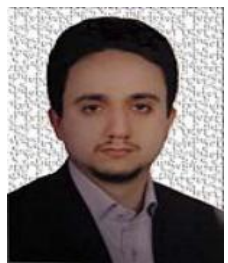

Mohammad Naser Hashemnia was born in Mashad, Iran, in 1984. He received his B.S. in Electrical Power Engineering from Ferdowsi University, Mashad, Iran, in 2006 and his M.S. in Electrical Power Engineering from the University of Tehran, Tehran, Iran, in 2008. $\mathrm{He}$ is currently a Ph.D. student at the Sharif University of Technology, Iran, where he is working on the modeling and control of Brushless Doubly Fed Machines (BDFMs). His main interests include the analysis and simulation of electric machines and advanced control methods for electrical drives.

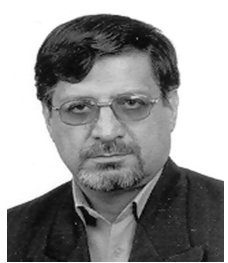

Jawad Faiz (M'90, SM97) received his M.S. in Electrical Engineering with First Class Honors from the University of Tabriz, Iran, in 1975. He received his $\mathrm{Ph} . \mathrm{D}$. in Electrical Engineering from the University of Newcastle upon Tyne, England, in 1988. Early in his career, he served as a Faculty Member at the University of Tabriz for 10 years. After obtaining his Ph.D. he rejoined the University of Tabriz where he held the position of Assistant Professor from 1988 to 1992 and Associate Professor from 1992 to 1997, and where he has been a Professor since 1998. Since February 1999 he has been working as a Professor in the School of Electrical and Computer Engineering, Faculty of Engineering, University of Tehran. He is currently the Director of the Center of Excellence on Applied Electromagnetic Systems. He has received a number of awards including the First Basic Research Award from the Kharazmi International Festival in 2007, the silver Einstein Medal for academic research from UNESCO, the First Rank Medal in Research from the University of Tehran in 2006, the Elite Professor Award from the Iran Ministry of Science, Research and Technology in 2004. He is the author of 158 papers in international journals and 166 papers in international conference proceedings. Dr. Faiz is a Senior Member of the Power Engineering, Industry Applications, Power Electronics, Industrial Electronics, Education and Magnetics Societies of the IEEE. He has also been a Member of the Iran Academy of Science since 1999. His teaching and research interests include switched reluctance and VR motors design, design and modeling of electrical machines and drives, transformer modeling and the design and fault diagnosis of electrical machinery. 